\title{
Pain Agnosia
}

National Cancer Institute

\section{Source}

National Cancer Institute. Pain Agnosia. NCI Thesaurus. Code C125664.

Loss of the ability to perceive and process pain. 